\title{
Source parameters of the earthquake sequence that occurred close to the BURAR array (Romania) between 24 June and 1 July 2011
} \author{
Mihail Diaconescu ${ }^{1}$, Mihaela Popa ${ }^{1}$ \\ ${ }^{1}$ National Institute for Earth Physics, Magurele, Romania \\ ${ }^{2}$ Academy of Romanian Scientists, Bucharest, Romania
}

Emilia Popescu ${ }^{1}$, Anica Otilia Placinta ${ }^{1,{ }^{\star}}$, Mircea Radulian ${ }^{1,2}$, Felix Borleanu ${ }^{1}$,

\author{
Article history \\ Received October 13, 2016; accepted February 3, 2017. \\ Subject classification: \\ Earthquake sequence, Spectral ratio, Empirical Green's function, Source parameters, Scaling relationships.
}

\begin{abstract}
The seismic activity in the Eastern Carpathians area is poorly recorded (a few hundreds of small-to-moderate earthquakes in the Romanian catalogue over the last century). The installation in 2002 of the high-performance Bucovina (BURAR) array in the Eastern Carpathians area contributed to a significant growth of the capacity to monitor local seismicity. As a consequence, the earthquake sequence occurred between 24 June and 1 July 2011 close to the BURAR array is the best seismic data set ever recorded for this area. The location of the events using all the available data provided by the real-time seismic network of the National Institute for Earth Physics suggests a NESW alignment along the western edge of the Avramesti - Suceava fault. This fault is crossing the Carpathian Foredeep underthrusting the foreland units to the orogeny area. The distribution of the first P-wave polarities is fitting the geometry of this fault, indicating predominant strike-slip faulting, with right-lateral movement. The compression axis oriented $\mathrm{E}-\mathrm{W}$ is in agreement with the stress field characterizing the region. We applied spectral ratios and empirical Green's function methods to estimate the source parameters (corner frequency, seismic moment, source duration, rise time) for the events with moment magnitudes higher than 2.5 belonging to this sequence. The results show a simple fracture model for the main shock of 24 June 2011 and an apparent constant stress drop scaling. Source parameter scaling relationships fit well the results obtained for other regions along the South-Eastern Carpathians and those which are typical for intra-continental areas.
\end{abstract}

\section{Introduction}

The Carpathians area is generally characterized by low seismic activity, except a strongly clustered activity concentrated at the Carpathians arc bend in the Vrancea region, in Romania [Ismail-Zadeh et al. 2012] and references therein). Whereas numerous investigations focused on the Vrancea seismicity, other areas of the Carpathians are still largely unexplored. The Eastern Carpathians segment in Romania is a good example in this respect. One explanation is the lack of high-quali- ty observations as a consequence of rare events in the region and poor monitoring infrastructure.

With the recent enlargement of the national seismic network [Neagoe et al. 2009, 2011; Popa et al. 2015] in the Eastern Carpathians area and installation of a high-performance array in the Bucovina region (Grigore et al., 2004; Borleanu et al., 2011; Ghica, 2011) the occurrence of an earthquake sequence in June - July 2011 in the northern part of the Eastern Carpathians (Figure 1), even if it was of moderate size, provided the best data set ever recorded for the region of the northern Moldavia and the possibility to apply advanced techniques to constrain source parameters.

The goal of the present paper is to study the sequence recorded between 24 June and 1 July 2011, taking advantage of the station coverage improvements in the region after 2005 and primarily of the running of the Bucovina (BURAR) array, located at about 50 $\mathrm{km}$ distance from the sequence epicentral area. This array of small aperture ( $\sim 5 \mathrm{~km}$ radius) was installed in 2002 in cooperation with the Air Force Technical Application Center (AFTAC) of the U.S.A. The array consists of 9 short-period elements with vertical sensors (BUR01, .., BUR09) and one 3-component broadband element (BUR31).

The sequence was generated at the western edge of an alignment extended from the Carpathian Foredeep and underthrust foreland units to the orogeny area (Avramesti-Suceava Fault). In order to estimate source parameters, we apply relative methods of deconvolution, such as empirical Green's functions and spectral ratios methods.

Similar investigations were performed for earthquake sequences generated in the southern segment 


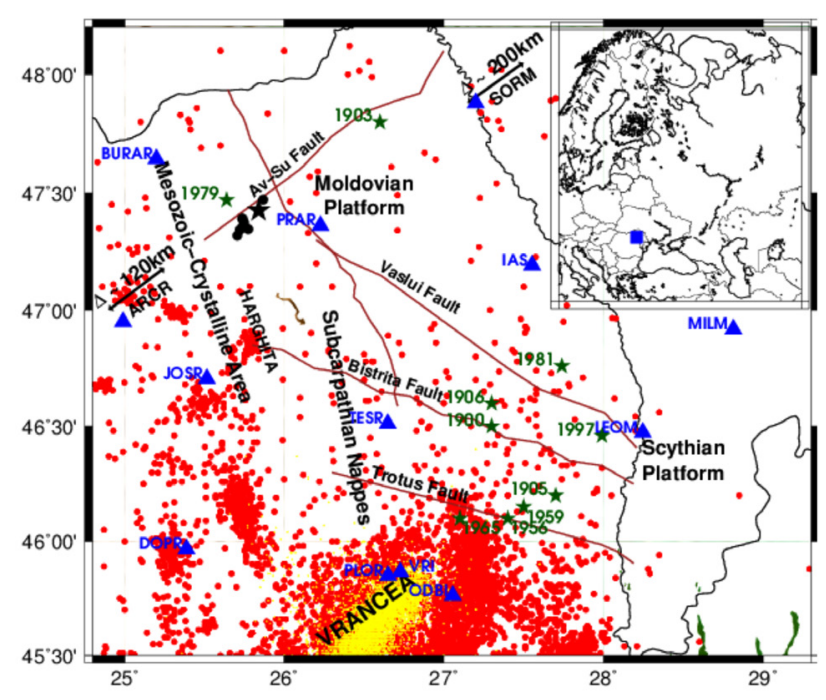

Figure 1. Sketch of seismotectonic map of the contact between the Moldavian and Scythian Platforms (east side) and Carpathians Orogen (west side). Setting in Europe is given in the upper right corner inset. The study region is marked by the blue square. The epicenters of the events recorded in the Romplus catalog (Oncescu et al., 1999) are plotted with red symbols for crustal earthquakes and yellow symbols for subcrustal earthquakes (Vrancea seismic region). The seismic stations of the National Institute for Earth Physics - Măgurele (Romania), located inside the map, in operation at that time, are plotted with solid triangles. The epicenters of the sequence of 24 June - 1 July 2011 are plotted as black dots (the main shock - black star). Significant events recorded in the region since 1900 are represented by green stars.

of the Carpathians [Enescu et al. 1996; Popescu 2000; Popescu and Radulian 2001; Popescu et al. 2003, 2011, 2012; Radulian et al. 2014, Placinta et al. 2016]. They basically consist of applying relative techniques of investigation, such as the spectral ratios and empirical Green's functions techniques that proved to be efficient in retrieving source parameters for seismic sequences.

First, source parameters are determined, and then, source scaling properties are subsequently investigated. Finally, the contribution of the new results in improving our understanding of the seismotectonics along the Carpathians orogeny is discussed.

\section{Regional seismotectonics}

The northern and central parts of the Moldavian Platform and Carpathians Orogen show a low-to-moderate crustal seismic activity (Figure 1), in contrast with the sharp concentration of earthquakes in the Vrancea region, located south of the Trotus Fault, at the Eastern Carpathians bending zone. According to the Romplus catalog [Oncescu et al. 1999], during January 1900 - April 2014, 874 small-to-moderate events $\left(1.1 \leq \mathrm{M}_{\mathrm{w}} \leq 5.5\right)$ occurred in this area, that we consider to belong mainly to a low background seismicity and to man-made activity. One single event has the magnitude $\mathrm{M}_{\mathrm{w}}$ greater than 5, but it is an event with no instrumental recordings, which occurred on 31 January 1900, 09:00, lon. 27.300E, lat. $46.500 \mathrm{~N}$. The earthquake is located close to the Bistriţa Fault. Most probably the magnitude $\left(\mathrm{M}_{\mathrm{w}}=5.5\right)$ is overestimated.

The locations of a few significant earthquakes in the region are represented in Figure 1. They can be associated with the principal faults crossing the platform region to the Carpathians orogen. Thus, we mention: events recorded along the Trotuş Fault that occurred on 18 April $1956\left(\mathrm{M}_{\mathrm{w}}=4.5\right), 12$ October $1959\left(\mathrm{M}_{\mathrm{w}}=4.1\right)$ and 16 September $1965\left(\mathrm{M}_{\mathrm{w}}=4.5\right)$, along the Bistriţa Fault on 17 October $1906\left(\mathrm{M}_{\mathrm{w}}=4.9\right)$ and 6 November $1997\left(\mathrm{M}_{\mathrm{w}}=3.1\right)$, along the Vaslui Fault on 8 November $1905\left(\mathrm{M}_{\mathrm{w}}=4.2\right)$ and 5 May $1981\left(\mathrm{M}_{\mathrm{w}}=3.2\right)$ and along the Avrămeşti-Suceava Fault on 20 January $1903\left(\mathrm{M}_{\mathrm{w}}=4.1\right), 20$ October 1979 $\left(\mathrm{M}_{\mathrm{w}}=3.7\right)$ and 24 June $2011\left(\mathrm{M}_{\mathrm{w}}=3.8\right)$. Note that all the events with magnitude larger than 4 took place until 1970, when the Romanian seismic network performance was modest and the accuracy in magnitude and location parameters was poor.

The relative enhancement of seismicity in the area between the Trotuş and Vaslui Faults reflects perhaps the transition from a stable segment (Moldavian Platform) to the active segment related to the Vrancea seismic activity, located south of the Trotuş Fault. The Trotuş Fault is an old Jurassic fracture, separating the Scythian Platform from the Moesian Platform, which looks like to be still active [Enciu et al. 2009, Van der Hoeven et al. 2005, Săndulescu 2009]. Another concentration of events is visible along the Neogene volcanic chain Călimani - Gurghiu - Harghita (but only events below $\mathrm{Mw} 4.0$ magnitude), located in the inner side of the Carpathians. However, the hourly distribution of the number of events indicates that a significant percentage of the activity in the Trotuş Fault region and especially in the Călimani - Gurghiu - Harghita region is due to quarry activities.

In the northern part of Moldavia the reported seismicity is sparse and is probably related to marginal fractures of the Moldavian Platform (part of the Eastern European Platform). In fact, the marginal fractures of the Platform are situated to the east of the epicenters [Polonic 1986]. In general, the epicenters are not following the main faults alignments excepting some clustering around central segment of the Trotus Fault. Non-coincidence between the epicenters and identified faults and the observation that the region exhibits an uplift neotectonic movement, lead to the idea that these earthquakes are caused by flexure that break and give small normal faults, with the eastern side having a tendency to upraise, while the western side of the fault is 
immobilized under molasses deposits. Such an interpretation is consistent with the generally accepted concept of termination of under pushing east-west movement of the foreland from the Moldavian Platform under Carpathians. The cluster of events recorded in the inner side of Carpathians (Harghita region) is rather associated with man-made activity due to quarry blast exploitation. The deficit of seismicity in comparison with the southern and south-western parts of Moldavia can be partly explained by the poor coverage of the Romanian seismic network in the northern part of Moldavia.

\section{Description of the earthquake sequence}

The crustal seismic sequence produced in the vicinity of Bucovina seismic array in June 2011 is a singular seismic phenomenon for this region, as far as we have available information. As Figure 1 shows, the background seismicity in this region is diffuse and poor, and therefore no preferential alignments of seismic sensibility and seismo-genetic contoured areas can be identified. However, the epicenters distribution of the studied seismic sequence apparently follows the alignment of the Avrămeşti - Suceava Fault (more precisely, the western edge of this fault) which crosses perpendicularly the entire fault system oriented NNW-SSE (Figure 1). Nevertheless, we should consider carefully this assumption taking into account not necessarily the location errors (the maximum axis or errors ellipsis is below $6 \mathrm{~km}$ ), but rather the configuration of stations with a large gap towards N-NE azimuth.

More than 40 events were identified as belonging to the sequence, but only 9 of them are well located (Table 1) using all the available data recorded by the real-time seismic network of National Institute for Earth Physics (short-period and broadband seismometers). We retained in our data set only the events located with minimum 6 stations and 8 phases. The locations were performed using LOCSAT routine which runs under ANTELOPE (BRTT) software, routinely operated by NIEP (National Institute for Earth Physics). To locate the events, we used P - and S - wave travel times manually read on the seismograms. The aftershocks spreading around the main shock epicenter (Figure 1) seem to indicate a unilateral rupture for this event along the Avrămeşti-Suceava Fault, dipping toward SE. Certainly, a rupture length close to $10 \mathrm{~km}$, as suggested by aftershocks distribution, extends far beyond the rupture dimension typically observed for an earthquake of magnitude 3.8 (no more than $1 \mathrm{~km}$ ). Therefore, the apparent length is most likely excessively large due to the uncertainties in the locations.
The number of stations used in location process varies from 6 (for the events of 24 June 2011, at 13:31 and 16:18) to 30 stations (for the main shock). Three stations belonging to the seismic network of the Republic of Moldova (LEOM, MILM, SORM) were included as well. The largest azimuthal gap between azimuthally adjacent stations (GAP) is around $120^{\circ}$, while the RMS value spans the interval 0.34 to $0.75 \mathrm{~s}$. The quality of reading the P- and S-wave phases is good for BURAR and 5 stations (SORM, TESR, MILM, JOSR, ARCR), while is generally poor for the more distant stations.

It is not possible to constrain the fault-plane solution of the main shock by inverting the first P-wave polarities (10 polarities picked with high confidence). However, to test if the Avrămeşti - Suceava alignment coincides with a possible nodal plane, we projected this fault on a lower hemisphere (Figure 2). The fault azimuth $\left(\mathrm{N} 48^{\circ} \mathrm{E}\right)$ and $\operatorname{dip}\left(56^{\circ}\right)$ are estimated simply from the geometry of the fault mapping in connection with the orientation of earthquake locations (Figure 1) and focal depth (Table 1). The conjugate nodal plane that approximates to some extent the distribution of reliable P-wave polarities is drawn in the same figure (plane 2). However, some stations are slightly outside the nodal plane 1 (fitting the assumed Avrămeşti - Suceava Fault). As a conclusion of our investigation, we can assume either that the Avrămeşti - Suceava Fault is shifted a bit to the NW relative to the epicenters (or

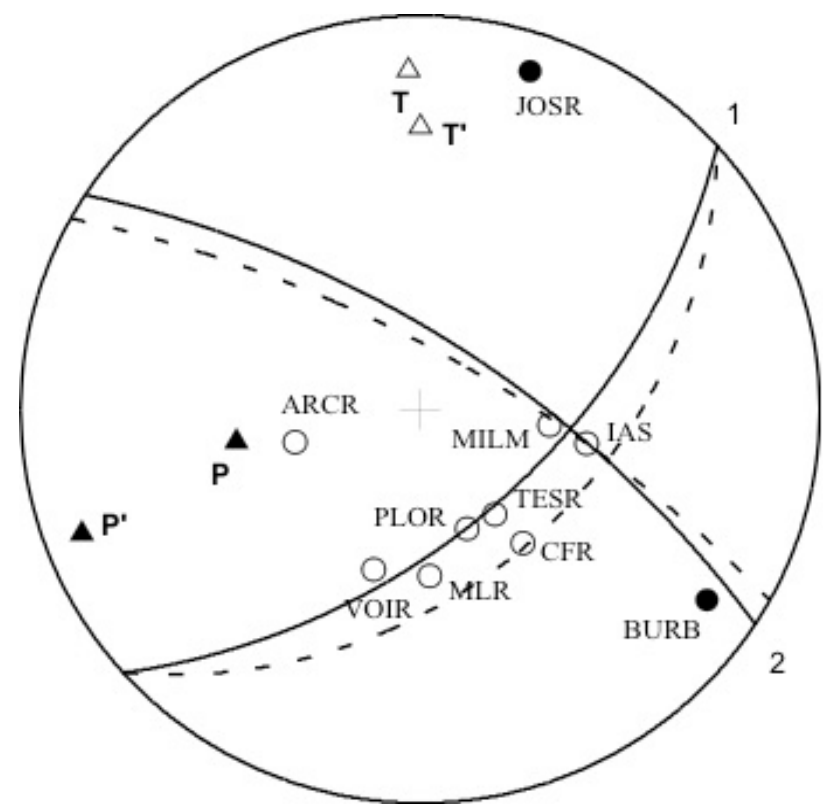

Figure 2. A possible fault plane solution of the main shock of the BURAR sequence, 24 June 2011, 13:08, $\mathrm{M}_{\mathrm{w}}=3.8$. The nodal planes with solid lines correspond with the Avrămeşti - Suceava Fault vs. epicentral distribution geometry. As shown in the text, a correction like that represented by dashed lines is matching better the P-wave polarities. Empty and solid circles are for compression and dilatation, respectively. 


\begin{tabular}{|c|c|c|c|c|c|c|c|c|c|}
\hline No. & $\begin{array}{c}\text { Date } \\
\text { (yyyy/m/day) }\end{array}$ & $\begin{array}{l}\text { Origin time } \\
\text { (hh:mm:ss) }\end{array}$ & $\begin{array}{l}\text { Lat. } \\
\left({ }^{\circ} \mathrm{N}\right)\end{array}$ & $\begin{array}{l}\text { Lon. } \\
\left({ }^{\circ} \mathrm{E}\right)\end{array}$ & $\begin{array}{c}\text { Depth } \\
(\mathrm{km})\end{array}$ & $M_{D} / M_{W}$ & $\begin{array}{c}\text { No. } \\
\text { stations }\end{array}$ & RMS & GAP \\
\hline 1. & $2011 / 6 / 24$ & $13: 06: 36.8$ & 47.399 & 25.768 & 11 & $2.9 / 3.1$ & 10 & 0.73 & 136 \\
\hline 2. & $2011 / 6 / 24$ & 13:08:40.5 & 47.372 & 25.777 & 10 & $4.6 / 3.8$ & 30 & 0.69 & 107 \\
\hline 3. & $2011 / 6 / 24$ & $13: 31: 29.1$ & 47.359 & 25.732 & 3 & $2.8 / 3.1$ & 6 & 0.34 & 110 \\
\hline 4. & $2011 / 6 / 24$ & $16: 18: 57.9$ & 47.355 & 25.756 & 5 & $2.6 / 2.9$ & 6 & 0.47 & 118 \\
\hline 5. & $2011 / 6 / 25$ & $00: 13: 47.3$ & 47.370 & 25.776 & 8 & $3.0 / 2.9$ & 7 & 0.57 & 119 \\
\hline 6. & $2011 / 6 / 25$ & $01: 43: 21.6$ & 47.344 & 25.765 & 10 & $3.2 / 3.1$ & 10 & 0.73 & 120 \\
\hline 7. & $2011 / 6 / 30$ & $21: 21: 18.5$ & 47.349 & 25.764 & 5 & $3.0 / 2.8$ & 22 & 0.65 & 116 \\
\hline 8. & $2011 / 6 / 30$ & $21: 22: 01.5$ & 47.345 & 25.730 & 4 & $2.9 / 2.8$ & 18 & 0.58 & 120 \\
\hline 9. & $2011 / 7 / 01$ & $22: 20: 25.4$ & 47.333 & 25.692 & 3 & $2.3 / 2.5$ & 15 & 0.75 & 116 \\
\hline
\end{tabular}

Table 1. Earthquake parameters for the study sequence. The main shock is marked with bold.

vice versa), or the focal depth of the main shock ( $h=10$ $\mathrm{km})$ is smaller $(\mathrm{h} \sim 5 \mathrm{~km})$.

A possible focal mechanism that we selected as the one best fitting all the polarities has the nodal plane 1 with the same azimuth $\left(\mathrm{N} 48^{\circ} \mathrm{E}\right)$, while the dip is lower $\left(43^{\circ}\right)$ - see nodal planes represented by dashed lines in the Figure 2. The focal mechanism is predominantly of strike-slip type, with right-lateral movement of the south-east compartment. The compression axis oriented E-W is in agreement with the stress field characterizing the region. A slight underthrust of the northern compartment under the southern compartment is also noticed (southern compartment is lifted and shifted towards south-west).

\section{Source parameters}

The relative deconvolution methods (spectral ratios and empirical Green's function deconvolution) are efficiently retrieving source parameters (seismic moment, source radius, rupture duration, rise time and stress drop) when waveforms from pairs of co-located events are available at common broadband stations [Frankel et al. 1986, Hough et al. 1989, Lindley 1994, Mueller 1985, Mori and Frankel 1990, Popescu et al. 2016]. Typically for this class of methods, the path, site and instrument effects are removed by deconvolving the waveform of a lower magnitude event from the main event waveform. The same approach was applied to other earthquake sequences occurred in the South-Eastern Carpathians area [Popescu 2000, Popescu and Radulian 2001, Popescu et al. 2003, 2011, 2012, Radulian et al. 2014, Placinta et al. 2016].

We applied the spectral ratios technique in parallel with the empirical Green's function deconvolution for the earthquakes given in Table 1. The quality of recordings for the last event ( 1 July) is poor and therefore, the application of relative methods in retrieving seismic source parameters cannot be properly done for this event. We limit in this case to the estimation of magnitude and seismic moment.

Spectral ratios depend essentially only on the source when the selection of earthquakes pairs is properly done and, in this case, it is not necessary to apply path, local and instrument response corrections. Another advantage of the method is the possibility to simultaneously determine the corner frequencies for both earthquakes of a selected pair, as long as the instrument is broadband and signal-to-noise ratio ( $\mathrm{SNR}$ ) is high enough in the frequency of interest. As concerns the source size, we obtain only the ratio of seismic moments. To estimate the absolute values, we need an independent determination for one event (reference value). We selected the largest earthquake as reference event and applied relation (3) below to compute its seismic moment. Then we compute the absolute values for all the other events using the spectral ratios values.

For a source model with uniform rupture and $\omega^{-2}$ spectral fall-off at high frequencies, the spectral ratios $(\mathrm{R}(\mathrm{f})$ ) can be approximated by the theoretical function:

$$
R(f) \frac{\Omega_{0}^{P}\left[1+\left(f / f_{c}^{G}\right)^{2_{\gamma}}\right]^{1 / 2}}{\Omega_{0}^{G}\left[1+\left(f / f_{c}^{P}\right)^{2_{\gamma}}\right]^{1 / 2}}
$$

where $\Omega_{0}{ }^{\mathrm{P}}, \Omega_{0}{ }^{\mathrm{G}}$ are the low-frequency asymptotes of amplitude spectra of principal and Green's earthquakes, and $\mathrm{f}_{\mathrm{c}}^{\mathrm{P}}, \mathrm{f}_{\mathrm{c}}^{\mathrm{G}}$ are the corresponding corner frequencies and $\gamma$ is the coefficient of the spectral fall-off at high frequency. Selecting as free parameters the ratio of seismic moments $\mathrm{a}=\lg \left(\Omega_{0}{ }^{\mathrm{P}} / \Omega_{0}{ }^{\mathrm{G}}\right)$ and the corner frequencies, we apply a nonlinear regression procedure in order to find the function (1) that best approximates observed spectral ratios.

We used all the components ( $\mathrm{Z}, \mathrm{E}, \mathrm{N})$ of the waveforms and all the common stations available to estimate the parameter values $a, f_{c}^{P}, f_{c}^{G}$ resulting from spectral ratio method application. The final estimates are the average values over all the specific values for different event 

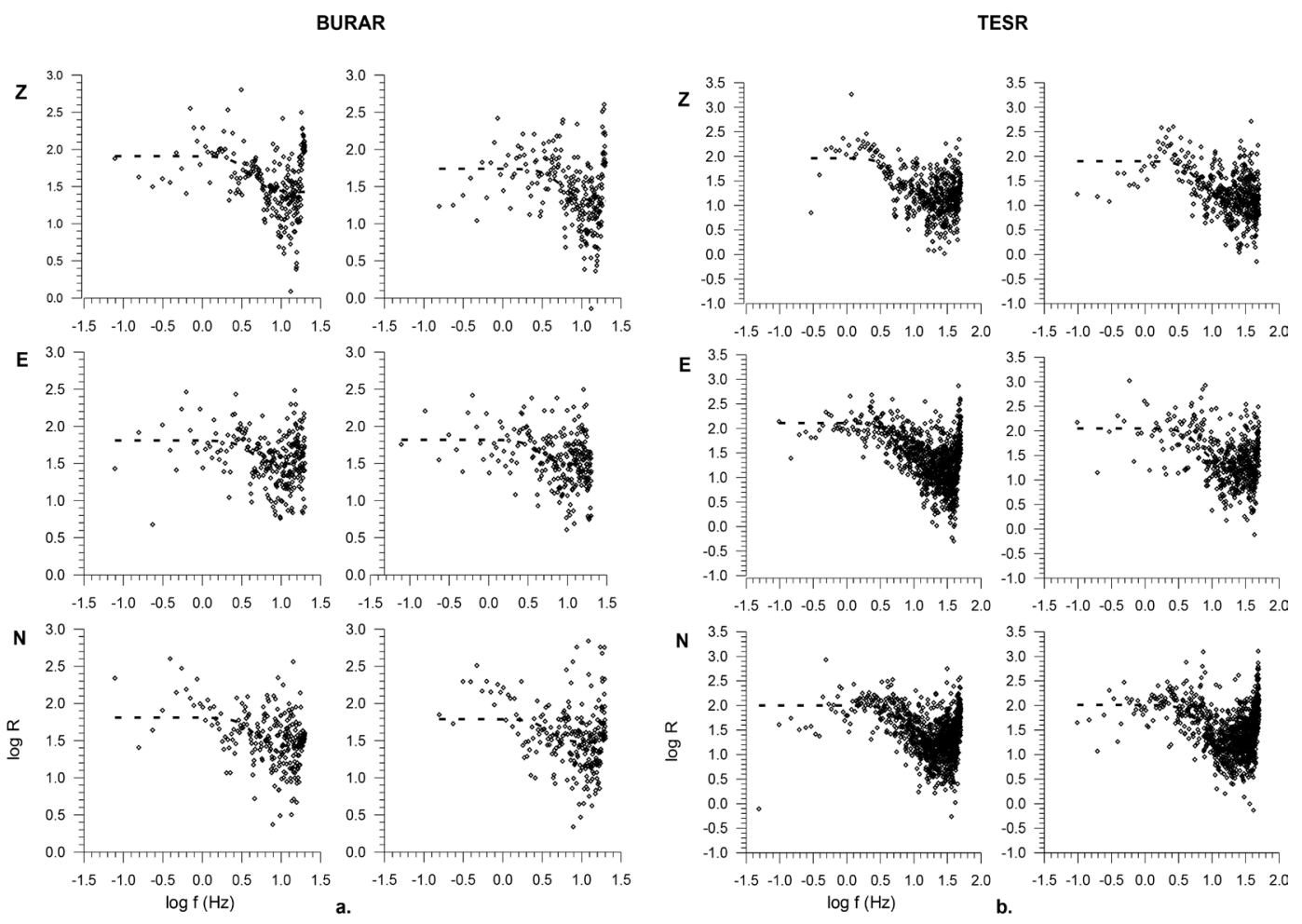

Figure 3. Spectral ratios obtained for the main event of 24 June 2011, 13:08 and empirical Green's functions of 30 June 2011, 21:21 $\left(\mathrm{M}_{\mathrm{W}}=2.8\right)$ - left column and 21:22 ( $\left.\mathrm{M}_{\mathrm{W}}=2.8\right)$ - right column: a) at BURAR station and $\left.\mathrm{b}\right)$ at TESR station. The dashed line represents the best approximation with a theoretical function given by relation (1).

pairs, stations and components. They are given in Annex. Examples of the spectral ratios for two earthquake pairs and two stations are plotted in the Figure 3.

The size of the rupture area is directly related to the corner frequency [Madariaga 1976]:

$$
r=k V_{s} / f_{c}
$$

$r$ representing the equivalent radius of the source while $\mathrm{k}$ is a constant value of 0.32 for $\mathrm{P}$ waves and 0.21 for $\mathrm{S}$ waves, $f_{c}$ is the corner frequency and $V_{S}$ is the $S$-wave velocity in the focus. With relationship (2) we determine the source radius from corner frequencies $\left(r^{G}{ }_{r s}\right.$ - radius of Green function obtained from spectral ratios, $\mathrm{r}_{\text {rs }}^{\mathrm{P}}$ radius of the main event obtained from spectral ratios).

The source radius estimated from corner frequency is an average between the estimations using $\mathrm{P}$-wave and S-wave corner frequencies. Since the relation (2) assumes a ratio about 1.5 of f $_{c} \mathrm{P} / \mathrm{f}_{\mathrm{c}} \mathrm{S}$ and for our data $\mathrm{f}_{\mathrm{c}} \mathrm{P} \mathrm{f}_{\mathrm{c}}^{\mathrm{S}}$, the radius computed from $\mathrm{f}_{\mathrm{c}} \mathrm{P}$ is systematically greater than the radius computed from $\mathrm{f}_{\mathrm{c}} \mathrm{S}$ roughly by a factor of 1.5 (for example, for main event,

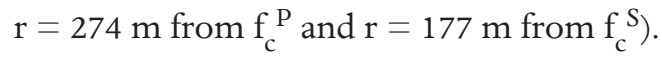

The seismic moment for the earthquakes analyzed in this study is estimated using:

$$
M_{0}=\left(4 \pi \rho V_{P}^{3} \Omega_{0} R\right) / R_{\theta \varphi}
$$

$\rho$ is the density at the source depth, VP is the velocity of P-waves at source depth, $\Omega_{0}$ is the long period displacement spectral level, $\mathrm{R}$ is the hypocentral distance and $\mathrm{R}_{\theta \phi}$ is the source radiation pattern (average values of 0.52 for $\mathrm{P}$ waves and 0.63 for $\mathrm{S}$ waves, according to [Aki and Richards 1980]. We adopted for $V_{p}$ and $\rho$ parameters the values as resulted from the velocity structure model estimated by Raileanu et al. [2012].

After seismic moment and source radius are calculated, the Brune stress drop [Brune 1970] is computed using:

$$
\Delta \sigma_{B}=\frac{7 M_{o}}{16 r^{3}}
$$

For the same pairs of events considered in the spectral ratios method, we applied in parallel the method of deconvolution with empirical Green's functions. The source rise time $\tau_{1 / 2}$, and the source duration $\tau$, for the main events, are estimated from the source time function each time it had a pulse - like shape. In this case the source radius was computed using Boatwright's formula [Boatwright 1980]:

$$
\left.r=\left(\tau_{1 / 2} v\right) / 1-v / \alpha \sin \theta\right)
$$

where $\tau_{1 / 2}$ is the source rise time, $v$ is the rupture velocity in the source, considered as $\mathrm{v}=0.9 \beta$ (with $\beta$ - S-wave velocity at the seismic source depth), $\alpha$ - P-wave velocity 

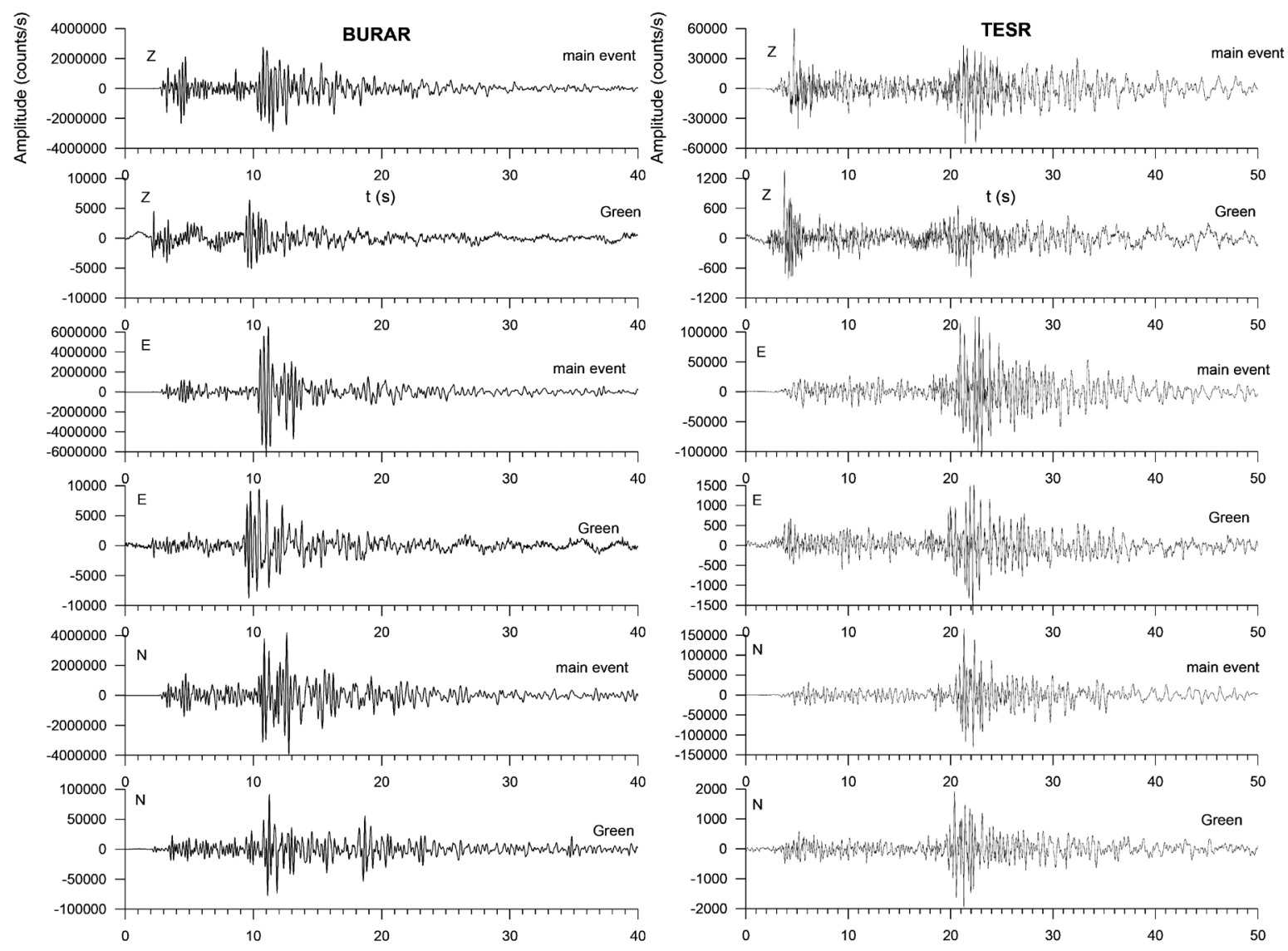

Figure 4. Examples of waveforms: a) main event of 24 June 2011, 13:08 and the associated empirical Green's function of 24 June 2011, 13:06 at the broadband element of the BURAR array (right); b) main event of 24 June 2011, 13:08 and the associated empirical Green's function of 25 June 2011, 01:43 at TESR station (left).

at the source depth, $\theta$ - the angle between the normal to the fault and the output direction of $\mathrm{P}$ waves from hypocenter. In case the main event has more Green's functions associated, rise time is the average of all obtained values of $\tau_{1 / 2}$ (different Green functions and different stations).

An example of main event - empirical Green's function pair is given in Figure 4. We plotted the main shock of 24 June 2011, 13:08 with two associated empirical Green's functions of 24 June, 13:06 and 25 June 2011, 01:43 as recorded at two stations, BURAR and TESR.

The average source time function for the main event, calculated as the arithmetic mean of the source time functions obtained for each pair of co-located events at each station, whenever these functions show well-defined patterns, is represented in Figure 5. In this case eight STFs were accepted for the average, including different station components. Source time function is a simple unipolar pulse, which supports the hypothesis of a homogeneous rupture pattern over $0.18 \mathrm{~s}$ duration.

We applied for the same selected pairs of events the method of deconvolution with empirical Green's functions to obtain the source duration $\tau$ and rise time $\tau_{1 / 2}$, for the main event, using the available stations for all co-located pairs.

Based on the seismic moment, corner frequency and source duration estimations, we determine the source area and stress drop using relations (2) - (4). To apply equation (4), we adopted an average value of $30^{\circ}$ for the take-off angle with respect to the normal to the fault. This angle takes into account source directivity effects which are likely to be negligible for such small earthquakes. For $\theta$ varying between 0 and $45^{\circ}$, the variation in $\mathrm{r}$ is slightly higher than $30 \%$. The difference between the source radius inferred from the duration and that inferred from corner frequency would suggest some inadvertencies in the parameters of relations (2) and (4).

The results are presented in Table 2 for the main event and for the empirical Green's function events.

\section{Scaling relationships}

The scaling relationships for earthquake sequences are valuable indicators of geotectonic peculiarities of the area under investigation. Such studies have been done previously for earthquake sequences occurred in the South-Eastern Carpathians foredeep region [Ene- 


\begin{tabular}{|c|c|c|c|c|c|c|c|c|}
\hline \multirow[t]{2}{*}{ Event } & \multirow{2}{*}{$\begin{array}{l}\text { Seismic moment } \\
(\mathrm{Nm})\end{array}$} & \multirow[t]{2}{*}{$\tau(\mathbf{s})$} & \multirow{2}{*}{$\mathbf{f}_{c}(\mathbf{H z})$} & \multicolumn{2}{|c|}{ Source radius (m) } & \multirow[t]{2}{*}{ Stress drop $(\mathrm{MPa})$} & \multirow[t]{2}{*}{$\mathbf{M}_{\mathrm{w}}$} & \multirow[t]{2}{*}{$M_{D}$} \\
\hline & & & & from $\tau_{1 / 2}$ & from $f_{c}$ & & & \\
\hline 24.06.2011, 13:08 & $1.01 \times 10^{15}$ & 0.180 & 3.72 & 282 & 227 & 37.8 & 3.8 & 4.6 \\
\hline Event & $\begin{array}{l}\text { Seismic moment } \\
(\mathrm{Nm})\end{array}$ & from $f_{c}{ }^{P}$ & & $\begin{array}{l}\text { from } f_{c}^{S} \\
\text { fadius }(\mathbf{m}) \\
\end{array}$ & average & Stress drop (MPa) & $\mathbf{M}_{\mathrm{w}}$ & $\mathbf{M}_{\mathrm{D}}$ \\
\hline $24.06 .2011,13: 06$ & $6.25 \times 10^{13}$ & 89 & & 72 & 81 & 51.5 & 3.1 & 2.9 \\
\hline $24.06 .2011,13: 31$ & $6.03 \times 10^{13}$ & 105 & & 70 & 88 & 38.7 & 3.1 & 2.8 \\
\hline $24.06 .2011,16: 18$ & $3.58 \times 10^{13}$ & - & & 71 & 71 & 43.8 & 2.9 & 2.6 \\
\hline $25.06 .2011,00: 13$ & $4.20 \times 10^{13}$ & 115 & & 83 & 99 & 18.9 & 2.9 & 3.0 \\
\hline $25.06 .2011,01: 43$ & $8.21 \times 10^{13}$ & 133 & & 84 & 109 & 27.7 & 3.1 & 3.2 \\
\hline $30.06 .2011,21: 21$ & $2.25 \times 10^{13}$ & 83 & & 53 & 68 & 31.3 & 2.8 & 3.0 \\
\hline 30.06.2011, 21:22 & $2.08 \times 10^{13}$ & 75 & & 53 & 64 & 34.7 & 2.8 & 2.9 \\
\hline 01.07.2011, 22:20 & $1.35 \times 10^{13}$ & - & & - & - & - & 2.5 & 2.5 \\
\hline
\end{tabular}

Table 2. Final source parameters for the main shock and for the empirical Green's functions used in this study.

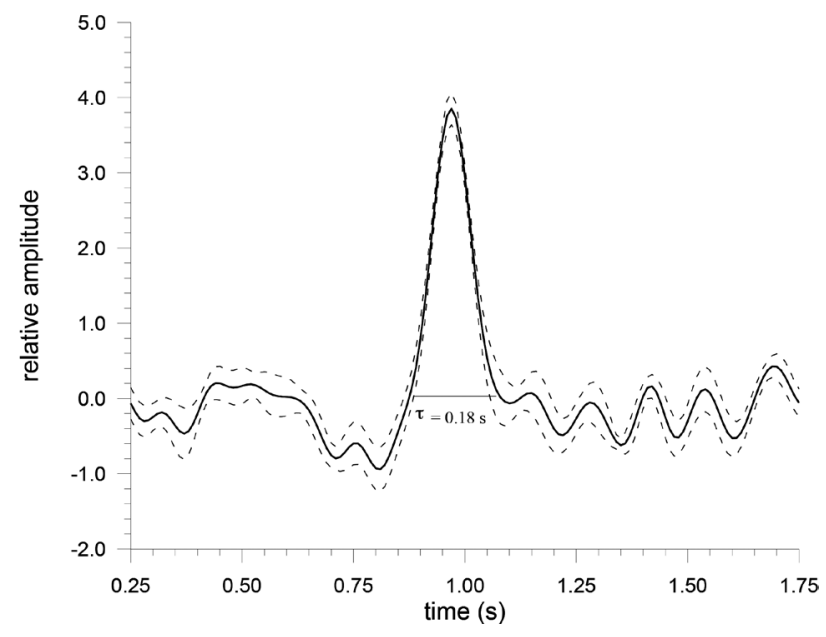

Figure 5. Source time function for the main shock of 24 June 2011, 13:08 (continuous line) calculated as the arithmetic mean of the values obtained for empirical Green's function deconvolution at all stations and components. The dashed lines represent the standard error.

scu et al. 1996, Popescu 2000, Popescu and Radulian 2001, Popescu et al 2003, 2011, 2012, Radulian et al. 2014, Placinta et al. 2016]. Up to now, there is no systematic investigation of the seismic activity recorded in the northern part of the Moldavian Platform. From this point of view, the determination of source parameters and of the corresponding scaling relationships for the sequence in the northern part of Moldavia provides new insights in the seismotectonics of this area.

The scaling of the seismic moment $\mathrm{M}_{0}$ with duration magnitude $M_{D}$ is shown in Figure 6. The data are approximated by the linear regression:

$$
\begin{gathered}
\log M_{0}=(0.88 \pm 0.13) M_{D}+(10.89 \pm 0.43) \\
R=0.94, \sigma=0.22
\end{gathered}
$$

However, the regression is based on only nine points, eight of them covering a narrow magnitude

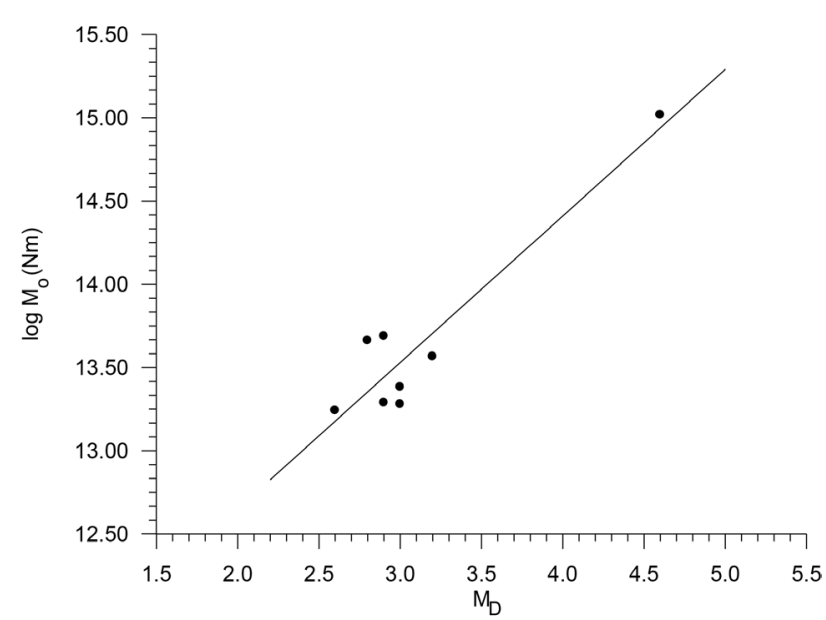

Figure 6. Scaling of seismic moment with duration magnitude.

distinguish signal from noise and duration tends to saturate. By contrary, for larger events the $\mathrm{S} / \mathrm{N}$ is higher and there is a higher probability to limit the duration measurement before some later phases.

Scaling of seismic moment with source radius (Figure 7) is well approximated by the linear regression:

$$
\begin{gathered}
\log M_{0}=(2.92 \pm 0.31) \log r+(8.04 \pm 0.60) \\
R=0.97, \sigma=0.14
\end{gathered}
$$

The slope of the regression line comes close to the theoretical value (3) which characterizes the seismic source scaling in case of homogeneous rupture process.

The scaling of stress drop with earthquake size (Figure 8) indicates a constant stress drop over the entire magnitude range. However, we should keep in mind that the uncertainties in stress drop are amplified relative to the source radius (corner frequency) uncertainties because of the power law dependence 


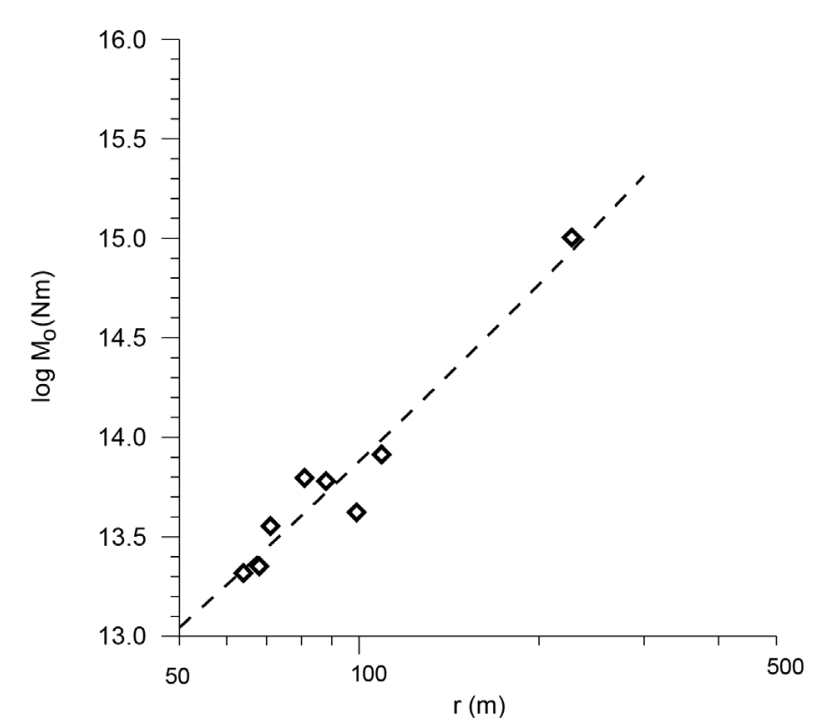

Figure 7. Scaling of seismic moment with source radius.

(equation (4)). The average stress drop value $(\sim 30-40$ $\mathrm{MPa}=300-400 \mathrm{bar})$ is characteristic for faulting processes in intra-continental areas (large stress drops). According to our results, the earthquake sequence was generated in an area that has been less fractured before.

It is interesting to notice (as shown in Table 2) that the highest value of the stress drop was recorded for the foreshock on 24 June at 13:06, in agreement with the hypothesis of a poorly fractured area prior the sequence triggering.

The scaling of the corner frequency and source duration with duration magnitude is represented in Figures 9-10. We combine in the graphical representation the estimates of the present study with estimates previously obtained for earthquakes generated in different other areas of the South-Eastern Carpathians

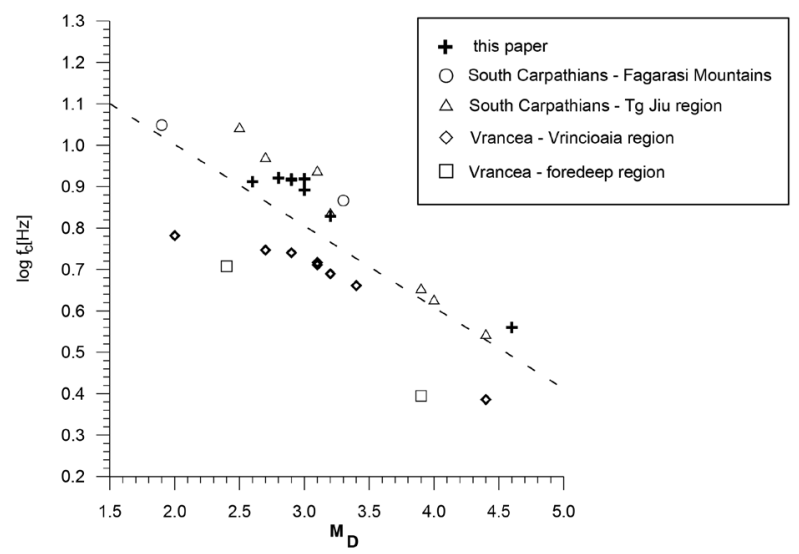

Figure 9. Scaling of corner frequency with duration magnitude. Data for South Carpathians from Radulian et al (2014), for Vrincioaia region from Popescu et al. (2012) and for Vrancea foredeep from Popescu et al. (2001) and Popescu et al. (2011). The regression line is estimated for all the data points.

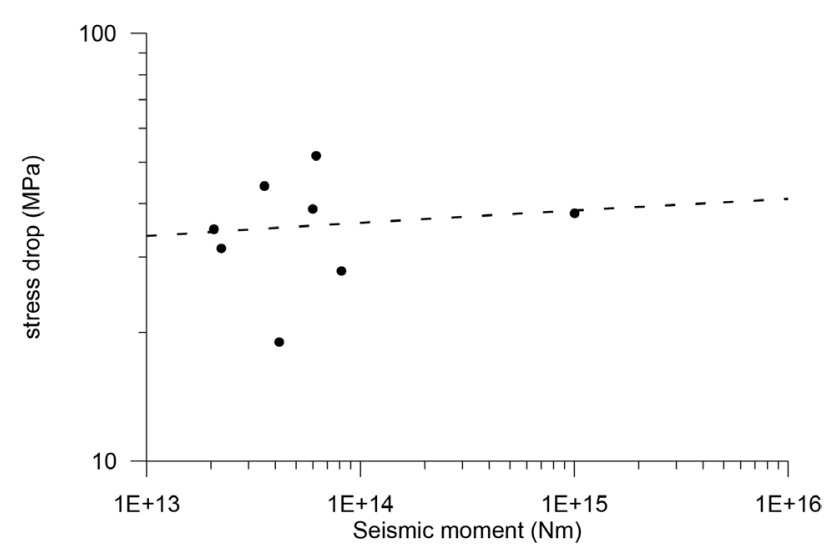

Figure 8. Scaling of stress drop with seismic moment. The regression line is close to a constant stress drop scaling around $35 \mathrm{MPa}$.

(see references above). In all cases, the same procedure was applied to retrieve corner frequency and source duration parameters.

The regression lines, approximating the scaling relationships, are:

$$
\begin{gathered}
\log f_{c}=-(0.20 \pm 0.03) M_{D}+(1.40 \pm 0.10) \\
r=0.76, \sigma=0.12 \\
\log \tau=(0.19 \pm 0.02) M_{D}-(1.50 \pm 0.09) \\
r=0.87, \sigma=0.06
\end{gathered}
$$

The slopes in the relations (8) and (9) are close each other in absolute value (with opposite signs). Therefore, we can assume that the corner frequency scales as a simple inverse of duration:

$$
\mathrm{f}_{\mathrm{c}} \sim \tau^{-1}
$$

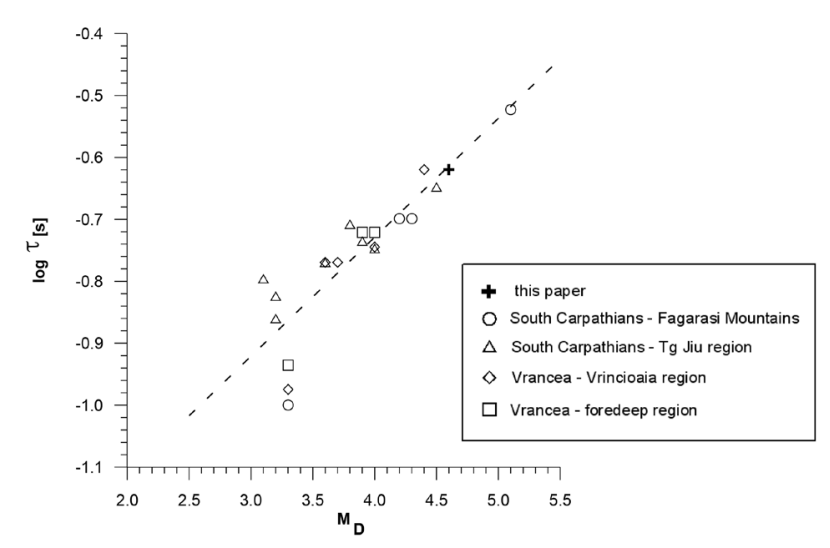

Figure 10. Scaling of source duration with duration magnitude. Data for South Carpathians from Enescu et al. (1996) and Radulian et al. (2014); for Vrincioaia region from Popescu et al. (2012) and for Vrancea foredeep from Popescu et al. (2001) and Popescu et al. (2011). The regression line is estimated for all the data points. 
in agreement with the relation (6) used by Boore [1983].

\section{Conclusions}

The earthquake sequence produced in the area adjacent to Bucovina Seismic Array (BURAR) between 24 June and 1 July 2011 is the single such a seismic phenomenon recorded until now in this region. Hypocenter locations using all the available data recorded by the real-time seismic network of the National Institute for Earth Physics (NIEP) show a NE-SW alignment along the Avrămeşti-Suceava Fault. It is likely that the study seismic sequence was a consequence of a sudden activation of the south-western edge of this fault. The fault plane solution is not constrained by the available data. The reliable P-wave polarities suggest a strikeslip faulting with a nodal plane close to the Avrămeşti-Suceava Fault.

The source parameters (corner frequency, seismic moment, source duration, rise time) are estimated by applying spectral ratios technique and empirical Green's function deconvolution. The results show a simple fracture model for the main shock of 24 June 2011, with a unipulse source time function and a constant stress drop scaling. The stress drop level is compatible with stress regime in intra-continental settings. Source parameter scaling relationships fit well the results obtained for other regions along the South-Eastern Carpathians and those which are typical for intra-continental areas.

Acknowledgements. Data used in the present study were provided by the National Institute for Earth Physics. The work was partially supported by the project "Nucleu"(PN 16350108$)$ of the National Plan for Research, Development and Innovation of the Romanian Ministry of National Education and by Project 69/2014, DARING, under The Executive Unit for Financing Higher Education, Research, Development and Innovation, Program Partnership in Priority Areas, Collaborative Applied Research Projects C2013.

\section{References}

Aki, K. and P. Richards (1980), Quantitative Seismology: Theory and Methods (Freeman, San Francisco). Boatwright, J.(1980), A Spectral Theory for Circular Seismic Sources: Simple Estimates of Source Duration, Dynamic Stress Drop, and Radiated Energy, Bull. Seismol. Soc. Am. 70, 1 -28.

Boore, D. M. (1983), Stochastic Simulation of High-Frequency Ground Motions Based on Seismological Models of the Radiated Spectra, Bull.Seism. Soc. Am. 73, 1865 -1894.

Borleanu, F., M. Popa, M. Radulian and J. Schweitzer
(2011), Slowness and Azimuth Determination for Bucovina Array (BURAR) Applying Multiple Signal Techniques, J. Journal of Seismology 15, Issue: 3, 431-442, DOI: $10.1007 /$ s10950-011-9228-9.

BRTT (2011), Evolution of the Commercial ANTELOPE Software; http:/ / www.brtt.com/docs/evolution.pdf.

Brune, J.N. (1970), Tectonic Stress and the Spectra of Seismic Shear Waves from Earthquakes, J. Geophys. Res., 75, 4997-5009.

Enciu, D.M., C.C. Knapp and J.H. Knapp (2009), Revised Crustal Architecture of the Southeastern Carpathian Foreland from Active and Passive Seismic Data,Tectonics 28, TC4013, doi: $10.1029 / 2008$ TC00238.

Enescu, D., E. Popescu and M. Radulian (1996), Source Characteristics of the Sinaia (Romania) Sequence of May-June 1993, Tectonophysics261, 39-49.

Frankel, A., J. Flechter, F. Vernon, L. Haar, J. Berger, T. Hanks and J. Brune (1986), Rupture Characteristics and Tomography Source Imaging of $\mathrm{ML}=$ 3 Earthquakes Near Anza, Southern California, J. Geophys. Res., 91, 12633 -12650.

Ghica, D.V. (2011), Detection Capabilities of the BURAR Seismic Array-Contributions to the Monitoring of Regional and Distant Seismicity, Journal of Seismology 01/2011; 15(3):487-506.

Grigore, A., B. Grecu, M.Rizescu, C. Ionescu, D. Ghicaand M. Popa (2004), A New Seismic Station in Romania: The Bucovina Seismic Array, Rev. Roum. GÉOPHYSIQUE, 48, $69-72$, Bucharest.

Ismail-Zadeh, A., L. Maţenco, M. Radulian, S. Cloetingh and G. F. Panza (2012), Geodynamics and Intermediate-Depth Seismicity in Vrancea (The South-Eastern Carpathians): Current State-of-the Art, Tectonophyiscs, 530 - $531,50-79$.

Hough, S.E., K. Jacob and R. Busby (1989), Ground Motions from a $\mathrm{M}=3.5$ Earthquake Near Massena, New York: Evidence for the Poor Resolution of Corner Frequency from Small Events, Seismol. Res. Lett., 60, 95 -99.

Lindley, G.T. (1994), Source Parameters of the 23 April 1992 Joshua Tree, California Earthquake, its Largest Foreshock and Aftershocks, Bull. Seism. Soc. Am., 84, 1051 - 1057.

Madariaga, R. (1976), Dynamics of An Expanding Circular Crack, Bull. Seismol. Soc. Am. 66, 639 -666.

Mori, J. and A. Frankel (1990), Source Parameters for Small Events Associated With the 1986 North Palm Springs, California Earthquake Determined Using Empirical Green Functions, Bull. Seism. Soc.Am., 80, 278 -285. 
Mueller, C.S. (1985), Source Pulse Enhancement by Deconvolutions With Empirical Green's Function,Geophys. Res. Lett., 12, 33 -36.

Neagoe, C. and C. Ionescu, Toward a Dense Real Time Seismic Network in Romania, Rom. Rep. Phys. 61 (2), 359 -366, (2009).

Neagoe, C., L.M. Manea and C. Ionescu (2011), Romanian Complex Data Center for Dense Seismic Network, Annals of Geophysics, 54, 1, 2011; doi: 10.4401/ag-4809.

Oncescu, M.C., V.I. Marza, M. Rizescuand M. Popa (1999), The Romanian earthquake catalogue between 9841997. Vrancea Earthquakes: Tectonics, Hazard and Risk Mitigation, Kluwer Academic Publishers, 43-47.

Placinta, A.O., E.Popescu, F. Borleanu, M. Radulian and M. Popa (2016), Analysis of source properties for the earthquake sequences in the south-western Carpathians (Romania), accepted for publication in Romanian Reports in Physics, 68, No. 3.

Polonic, G. (1986), Structure of the Crystalline Basement in Romania, Rev. Roum. Geophysique, 40, 57-69, Bucharest.

Popescu, E. (2000), Complex Study of the Earthquake Sequences on the Romanian Territory, $\mathrm{PhD}$ Thesis, Institute of Atomic Physics, Bucharest, (in Romanian).

Popescu, E. and M. Radulian (2001), Source Characteristics of the Seismic Sequences in the Eastern Carpathians Foredeep Region (Romania), Tectonophysics, 338, 325-337.

Popescu, E., M. Popa and M. Radulian (2003), Efficiency of the Spectral Ratio Method to Constrain the Source Scaling Properties of the Vrancea (Romania) Subcrustal Earthquakes, Rom. Rep. Phys.55, 149-169.

Popescu, E., C. Neagoe, M. Rogozea, I.A. Moldovan, F. Borleanu and M. Radulian (2011), Source Parameters for the Earthquake Sequence Occurred in the Ramnicu Sarat Area (Romania) November-December 2007, Rom. Journ. Phys.56, 265-278.

Popescu, E., F. Borleanu, M. Rogozea and M. Radulian (2012), Source Analysis for Earthquake Sequence Occurred in Vrancea (Romania) Region on 6 to 30 September 2008, Romanian Report Phys., 64, No. 2.

Popescu, E., M. Radulian and A.O. Placinta (2016), Scaling properties for the Vrancea subcrustal earthquakes: An overview, in "Effects and Lessons from November 10th, 1940 Vrancea Earthquake" Proceedings of the Symposium Commemorating 75 Years from November 10, 1940 Vrancea Earthquake (eds. R. Vacareanu, C. Ionescu), Springer Natural Hazards, 235 - 252.

Radulian, M., E. Popescu, F. Borleanu and M. Diaconescu (2014), Source Parameters of the December 2011 - January 2012 Earthquake Sequence in Southern Carpa- thians, Romania, Tectonophysics, 623, 23-38.

Răileanu, V., D. Tătaru and B. Grecu (2012), Crustal Models in Romania - I. Moesian Platform, Romanian Report Phys., 64, No.2, 539-554.

Săndulescu, M., (2009), The Geotectonic Framework of a Peculiar Seismogenetic Area - the Vrancea Seismic Zone (Romanian Carpathians), Proc. Rom. Acad., Series $\mathrm{B}, 2$-3, $151-157$.

Van der Hoeven, A.G.A., V. Mocanu, W. Spakman, M. Nutto, A. Nuckelt, L. Maţenco, L. Munteanu, C. Marcu and A.C. Ambrosius (2005), Observations of Present-Day Tectonic Motions in the Southeastern Carpathians: Results of the ISES/CRC-461 GPS Measurement, Earth Planet. Sci. Lett., 239, 177 - 184.

\footnotetext{
${ }^{\star}$ Corresponding author: Anica Otilia Placinta National Institute for Earth Physics, Magurele, Ilfov, Romania; email: anca@infp.ro.
}

2017 by Istituto Nazionale di Geofisica e Vulcanologia. All rights reserved 


\section{ANNEX}

Parameter values "a", fcP, fcG resulting from spectral ratios method analysis. Event $\mathrm{P}$ corresponds to main event (event 2 in Table 1). The number assigned to each Empirical Green's Function (EGF) is the same as in Table 1.

\begin{tabular}{|c|c|c|c|c|c|c|c|c|c|}
\hline \multirow[t]{2}{*}{$\begin{array}{l}\text { Pair P-1 } \\
\text { EGF:11/06/24, 13:06 }\end{array}$} & \multicolumn{3}{|c|}{$\begin{array}{c}\text { a } \\
(\text { spectral ratio) }\end{array}$} & \multicolumn{3}{|c|}{$\begin{array}{c}\mathbf{f}_{\mathbf{c}}(\mathbf{H z}) \\
\text { (main shock) }\end{array}$} & \multicolumn{3}{|c|}{$\begin{array}{c}\mathbf{f}_{\mathbf{c}}(\mathbf{H z}) \\
\text { (Green function) }\end{array}$} \\
\hline & $\mathbf{Z}$ & $\mathbf{E}$ & $\mathbf{N}$ & $\mathbf{Z}$ & $\mathrm{E}$ & $\mathbf{N}$ & $\mathbf{Z}$ & $\mathbf{E}$ & $\mathbf{N}$ \\
\hline BURB & 1.79 & 1.87 & 1.84 & 4.79 & 3.89 & 3.89 & 7.80 & 5.21 & 5.21 \\
\hline SORM & - & 1.65 & 1.84 & - & 3.38 & 3.30 & - & 7.00 & 7.92 \\
\hline TESR & 1.84 & 1.70 & 1.79 & 3.22 & 3.35 & 3.24 & 10.40 & 9.40 & 9.50 \\
\hline Average/component & $\begin{array}{c}1.820 \\
\pm\end{array}$ & $\begin{array}{c}1.740 \\
\pm\end{array}$ & $\begin{array}{c}1.823 \\
\pm\end{array}$ & $\begin{array}{c}4.00 \\
\pm\end{array}$ & 3.5 & & $\begin{array}{c}9.10 \\
\pm\end{array}$ & & \\
\hline
\end{tabular}

Average/EGF

$1.793 \pm 0.079$

$3.633 \pm 0.541$

$8.235 \pm 1.223$

\begin{tabular}{|c|c|c|c|c|c|c|c|c|c|}
\hline \multirow[t]{2}{*}{$\begin{array}{l}\text { Pair P-3 } \\
\text { EGF:11/06/24, 13:31 }\end{array}$} & \multicolumn{3}{|c|}{$\begin{array}{c}\text { a } \\
\text { (spectral ratio) }\end{array}$} & \multicolumn{3}{|c|}{$\begin{array}{c}\mathbf{f}_{\mathbf{c}}(\mathbf{H z}) \\
\text { (main shock) }\end{array}$} & \multicolumn{3}{|c|}{$\begin{array}{l}\mathbf{f}_{\mathbf{c}}(\mathbf{H z}) \\
\text { (Green function) }\end{array}$} \\
\hline & $\mathbf{Z}$ & $\mathbf{E}$ & $\mathbf{N}$ & $\mathbf{Z}$ & $\mathbf{E}$ & $\mathbf{N}$ & $\mathbf{Z}$ & $\mathbf{E}$ & $\mathbf{N}$ \\
\hline BURB & 1.91 & 1.93 & 1.98 & 3.71 & 4.15 & 3.94 & 7.50 & 6.80 & 7.20 \\
\hline TESR & 2.07 & 1.92 & 1.93 & 3.28 & 3.55 & 3.78 & 9.32 & 9.00 & 10.00 \\
\hline Average/component & $\begin{array}{c}1.990 \\
\pm \\
0.113\end{array}$ & $\begin{array}{c}1.925 \\
\pm \\
0.007\end{array}$ & $\begin{array}{c}1.955 \\
\pm \\
0.035\end{array}$ & $\begin{array}{c}3.495 \\
\pm \\
0.304\end{array}$ & 3.85 & & $\begin{array}{c}8.410 \\
\pm \\
1.287\end{array}$ & 8.25 & 509 \\
\hline Average/EGF & \multicolumn{3}{|c|}{$1.957 \pm 0.061$} & \multicolumn{3}{|c|}{$3.735 \pm 0.303$} & \multicolumn{3}{|c|}{$8.330 \pm 0.113$} \\
\hline $\begin{array}{l}\text { Pair P-4 } \\
\text { EGF:11/06/24, 16:18 }\end{array}$ & \multicolumn{3}{|c|}{$\begin{array}{c}\text { a } \\
\text { (spectral ratio) }\end{array}$} & \multicolumn{2}{|c|}{$\begin{array}{c}\mathbf{f}_{\mathbf{c}}(\mathbf{H z}) \\
\text { (main shock) }\end{array}$} & \multicolumn{4}{|c|}{$\begin{array}{c}\mathbf{f}_{\mathbf{c}}(\mathbf{H z}) \\
\text { (Green function) }\end{array}$} \\
\hline & $\mathbf{Z}$ & $\mathbf{E}$ & $\mathbf{N}$ & $\mathbf{Z}$ & $\mathbf{E}$ & $\mathbf{N}$ & $\mathbf{Z}$ & $\mathbf{E}$ & $\mathbf{N}$ \\
\hline BURB & - & 2.44 & 2.37 & - & 4.92 & 4.66 & - & 9.00 & 7.00 \\
\hline SORM & - & 2.09 & 2.14 & - & 3.18 & 3.96 & - & 6.65 & 10.00 \\
\hline Average/component & - & $\begin{array}{c}2.265 \\
\pm \\
0.247\end{array}$ & $\begin{array}{c}2.255 \\
\pm \\
0.163\end{array}$ & - & $\begin{array}{c}4.180 \\
\pm \\
0.780\end{array}$ & & - & 8.1 & 1.604 \\
\hline Average/EGF & \multicolumn{3}{|c|}{$2.260 \pm 0.171$} & \multicolumn{3}{|c|}{$3.735 \pm 0.303$} & \multicolumn{3}{|c|}{$8.330 \pm 0.113$} \\
\hline $\begin{array}{l}\text { Pair P-5 } \\
\text { EGF:11/06/25, 00:13 }\end{array}$ & \multicolumn{3}{|c|}{$\begin{array}{c}\text { a } \\
(\text { spectral ratio })\end{array}$} & \multicolumn{3}{|c|}{$\begin{array}{c}\mathbf{f}_{\mathbf{c}}(\mathbf{H z}) \\
\text { (main shock) }\end{array}$} & \multicolumn{3}{|c|}{$\begin{array}{c}\mathbf{f}_{\mathbf{c}}(\mathbf{H z}) \\
\text { (Green function) }\end{array}$} \\
\hline & $\mathbf{Z}$ & $\mathbf{E}$ & $\mathbf{N}$ & $\mathbf{Z}$ & $\mathbf{E}$ & $\mathbf{N}$ & $\mathbf{Z}$ & E & $\mathbf{N}$ \\
\hline BURB & 2.13 & 2.20 & 219 & 3.89 & 3.59 & 3.80 & 6.56 & 5.39 & 5.61 \\
\hline SORM & 1.92 & 2.16 & 2.18 & 4.62 & 3.20 & 3.22 & 9.52 & 8.85 & 10.00 \\
\hline TESR & 2.13 & 2.02 & 2.18 & 2.97 & 4.61 & 3.29 & 10.00 & 8.30 & 9.20 \\
\hline Average/component & $\begin{array}{c}2.060 \\
\pm \\
0.121\end{array}$ & $\begin{array}{c}2.127 \\
\pm \\
0.095\end{array}$ & $\begin{array}{c}2.183 \\
\pm \\
0.006\end{array}$ & $\begin{array}{c}3.827 \\
\pm \\
0.827\end{array}$ & 3.61 & & $\begin{array}{c}8.693 \\
\pm \\
1.863\end{array}$ & 7.89 & 934 \\
\hline Average/EGF & & $23 \pm 0.0$ & & & $2 \pm 0.5$ & & & $3 \pm 0.5$ & \\
\hline
\end{tabular}


POPESCU ET AL.

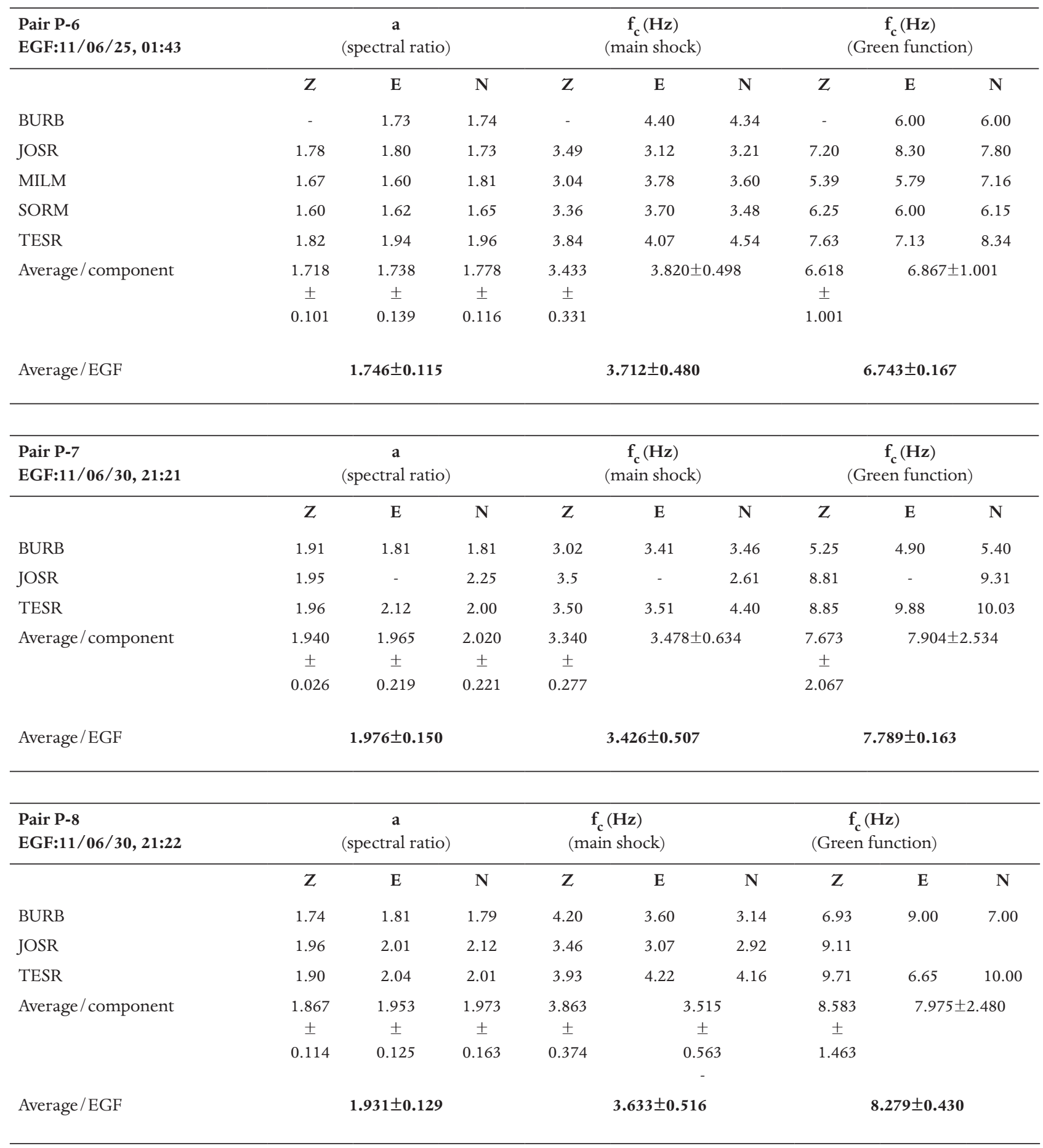

